\title{
POTENTIAL USE OF PHASE CHANGE MATERIALS IN GREENHOUSES HEATING: COMPARISON WITH A TRADITIONAL SYSTEM
}

\author{
Claudio Caprara, Giovanni Stoppiello
}

\section{Introduction}

In recent years great attention has been paid in heat storage systems implementation, in order to save and better use waste heat from industrial applications, to increase overall efficiency of cogeneration units and to level off energy supply in such applications were high peaks are registered. In this third case, thermal solar energy systems are maybe the main representative technology where an high variability of energy supply is registered during daytime. Traditionally, available and surplus heat has been stored in the form of sensible heat, by using equipments where water has typically been used as a storage medium. In recent years new heat storing technologies have been developed, mostly concerning latent heat storage methods and phase change materials (PCMs) utilization [Mehling 2003; Yagi 1995; Zalba 2003]. These materials have been found out of considerable interest especially for their operational advantages in low temperature fluctuations, smaller size units and therefore lower weights per unit of storage capacity.

A large variety of materials can be potentially used as latent heat storing medium [Zalba 2003]: hydrate salts, organic compounds (paraffin), fatty acids, etc. Each of them has its own physical characteristics and phase change temperature. Therefore, an high grade of operational flexibility has been already reached for these particular applications.

In this work, the technical behaviour of a latent heat storage system was investigated in comparison with a traditional water tank heat storage one. They were supposed to be integrated with thermal solar collector modules in order to keep constant temperature inside a greenhouse. Indeed, thermal solar collectors

Paper received 08.01.2009; accepted 21.07.2009

Dr. Claudio Caprara, Researcher, Ing. Giovanni Stoppiello, $\mathrm{PhD}$ student, Agricultural Economics and Engineering Dept., University of Bologna, Via G.Fanin 50, 40127 Bologna, Italy, e-mail of corresponding author: claudio.caprara@unibo.it are especially suitable in low temperature applications, since their efficiency decreases as the temperature of heat transfer fluid (HTF) passing through them increases, because of heat losses [Gemelli 2001].

Geometry of latent heat storage equipment was determined and dimensions of both of the systems were estimated, as well as the solar collectors ones, on the basis of greenhouse heat demand during the period corresponding to the first step of vegetable plants growth (aubergines, in these case). Localization was chosen as Bologna countryside.

Thermal behaviour of heat storage units was detected as a response of their simultaneous thermal energy inputs (energy supplied from solar collectors) and outputs (water heating for greenhouse temperature control) during the day.

The results were achieved by using an analytical and computational model already developed for PCMs applications [Caprara 2008], in which thermal energy demand, energy source and technical characteristics of the systems were modified.

PCMs properties, geometrical characteristics of collectors and heat exchange devices as well as greenhouse dimensions are inserted as input data of the software tool, so that different system configurations can be considered.

The main goal of this work was to investigate technical differences between these two heat storage units, especially in the case they are used in low temperature applications. On the other hand, since a real case study was considered, the results of the developed analytical model can be also seen as preliminary indications for design accomplishments.

\section{Materials and Methods}

The analytical model that has been developed in this work is based on an overall thermal energy balance in which greenhouse building, thermal solar collector modules and heat storage units are involved.

In order to keep constant the temperature inside the greenhouse $\left(18^{\circ} \mathrm{C}\right.$ was chosen as the best temperature for the first steps of aubergines plants growing, as a 
real case study), its heat losses towards the surrounding environment need to be balanced by heat supply from solar collectors. Because these two opposite energy terms show their own daily peaks in different hours of the day, heat storage units are required.

Heat losses from greenhouse depend on ambient external temperature of air, while thermal collector efficiency is affected by solar radiation. Therefore, for running model simulations, these climate conditions had to be set. In this case, a typical day of Bologna countryside in October (as the usual period for aubergines planting) was chosen as reference day ${ }^{1}$.

Solar radiation was calculated through the estimation of solar angles for each hour of the reference day, considering geographical coordinates of Bologna [Raffellini 2008]. Figure 1 and 2 show climate conditions as they are inserted as input data into the simulation model.

Greenhouse dimensions were chosen as usual ones for small areas in local territory. They are shown in figure 3. Total volume of the building is $840 \mathrm{~m}^{3}$.

In the following paragraphs, each term of the mentioned heat balance, respectively corresponding to

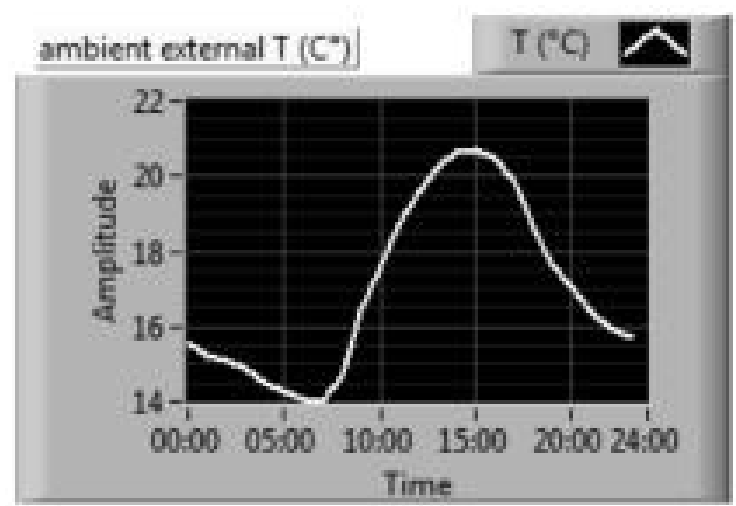

Fig. 1 - Ambient external temperature during daytime, for a typical October day in Bologna $\left({ }^{\circ} \mathrm{C}\right)$.

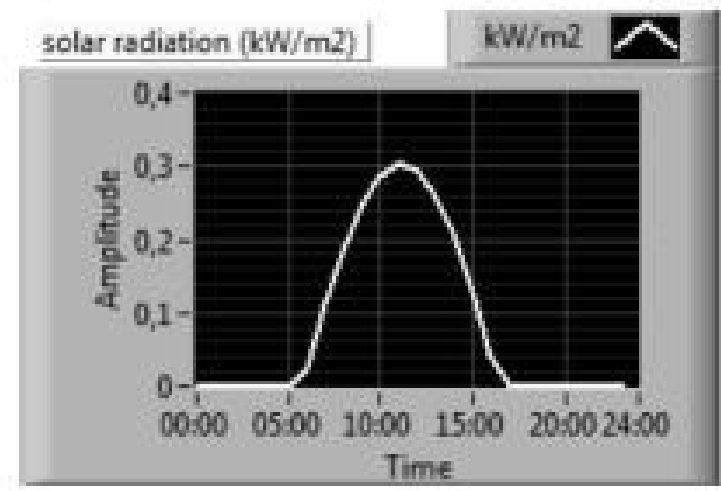

Fig. 2 - Solar radiation during daytime, for a typical October day in Bologna $\left(\mathrm{kW} / \mathrm{m}^{2}\right)$.

\footnotetext{
1 External temperature data were furnished by ARPA, Emilia Ro-
} magna

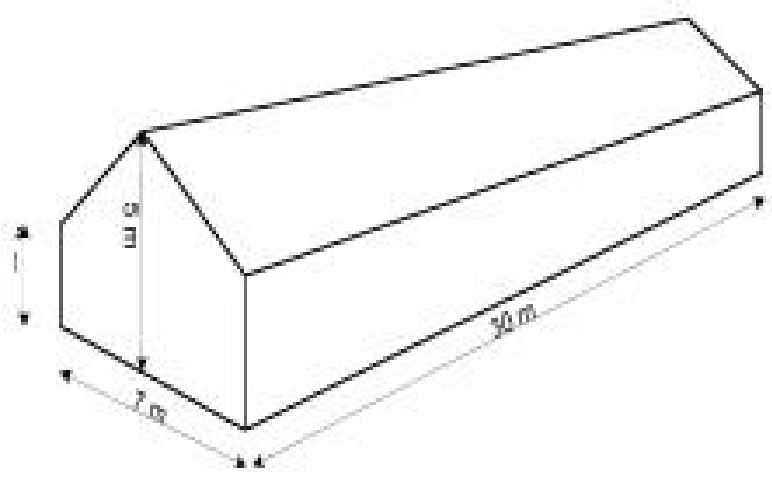

Fig. 3 - Greenhouse dimensions.

greenhouse heat loss, solar collectors energy supply and heat storage is described with more details.

\subsection{Greenhouse heat losses}

Total heat loss can be estimated as the sum of three different phenomena [Worley 2005]: conductive/convective heat exchange from external surfaces of the greenhouse, air infiltration and ventilation, heat exchange between greenhouse and the ground underneath and beside the structure. Besides them, heat loss by long-wave radiation of greenhouse structure should be considered. Nevertheless, the results of the model trials have proven this term is of the same order of magnitude of solar radiation on the greenhouse during daylight time. Therefore, in order to simplify model development by neglecting inner air temperature fluctuations during the day (it is fixed at constant temperature for the whole day), these two opposite terms are supposed to be counter-balanced and thus they are not considered in the heat balance.

Conductive and convective heat exchange is calculated by the following equation (ANSI/ASAE EP406.4 2003):

$$
Q_{c}=\frac{A \cdot\left(T_{i v}-T_{\text {adi }}\right)}{R}
$$

$A$ : total greenhouse exposed surface $\left(\mathrm{m}^{2}\right)$.

$T_{\text {in }}-T_{\text {out }}$ : difference of temperature between inside and outside the greenhouse $\left({ }^{\circ} \mathrm{C}\right)$.

$R$ : overall resistance to heat flow $\left(\mathrm{m}^{2}{ }^{\circ} \mathrm{C} / \mathrm{W}\right)$

$R$ value depends on the material of the structure and it is commonly estimated for the entire greenhouse. In this case, a polyethylene, double layer separated greenhouse was chosen. The overall resistance $R$ for this type of greenhouse is valued as $0.250 \mathrm{~m}^{2}{ }^{\circ} \mathrm{C} / \mathrm{W}$ (ANSI/ASAE EP406.4 2003).

Heat loss besides the structure is estimating as heat loss along greenhouse perimeter by means of the following relation [Parker 1991]:

$$
Q_{p}^{\prime}=L \cdot P \cdot\left(T_{w}-T_{a x}\right)
$$

$L$ : perimeter of the greenhouse (m) 
$P$ : perimeter heat loss coefficient $\left(\mathrm{W} / \mathrm{m}{ }^{\circ} \mathrm{C}\right)$

Perimeter heat loss coefficient $P$ is different for insulated or uninsulated greenhouses. In this case, uninsulated one was considered with the corresponding $P$ value as $1.38 \mathrm{~W} / \mathrm{m}^{\circ} \mathrm{C}$ (Parker 1991).

Heat loss to the ground underneath is calculated as conductive heat exchange through the soil.

A ground depth of $0.5 \mathrm{~m}$ was considered as the one at which no daily temperature fluctuations are detectable and a constant temperature can be supposed [Casalicchio 2006]. This value was chosen as $17^{\circ} \mathrm{C}$ in October, as reported by Basso, 1995. Thermal conductivity of soil was fixed as $1.5 \mathrm{~W} / \mathrm{m}{ }^{\circ} \mathrm{C}$ [Cavazza 1981].

Heat loss to the ground beneath is thus calculated as follows:

$$
Q_{a}=\frac{A_{z} \cdot \lambda_{n} \cdot\left(T_{n}-T_{n}\right)}{s}
$$

$A_{g}$ : ground area underneath the greenhouse $\left(\mathrm{m}^{2}\right)$.

$T_{i n}-T_{g}:$ difference of temperature between inner greenhouse air and soil at $s$ depth $\left({ }^{\circ} \mathrm{C}\right)$.

$s$ : soil depth at which temperature is constant during daytime.

$\lambda_{s}$ : thermal conductivity of soil $\left(\mathrm{W} / \mathrm{m}{ }^{\circ} \mathrm{C}\right)$

Air infiltration heat loss depends on the age and the maintenance of the greenhouse, as well as its materials and openings. Neglecting latent heat of inner greenhouse humidity, it is grossly calculated by the equation [ANSI/ASAE EP406.4 2003]:

$$
Q_{a}=\frac{\rho_{a r} \cdot C P_{n} \cdot V \cdot C \cdot\left(T_{w}-T_{a r}\right)}{3600}
$$

$V:$ volume of greenhouse $\left(\mathrm{m}^{3}\right)$

$C$ : number of air exchanges per hour $\left(\mathrm{h}^{-1}\right)$

$\rho_{\text {air }}:$ air density $\left(\mathrm{kg} / \mathrm{m}^{3}\right)$

$C p_{\text {air }}$ : air specific heat $\left(\mathrm{J} / \mathrm{kg}{ }^{\circ} \mathrm{C}\right)$

Also $C$ depends on greenhouse age and materials. In this case its value was estimated as $0.75 \mathrm{~h}^{-1}$ [ANSI/ASAE EP406.4 2003]:

As already mentioned, overall heat loss for the greenhouse is the sum of the amounts previously calculated:

$$
\underline{Q}_{1}=\underline{Q}_{e}+\underline{Q}_{p}+\underline{Q}_{p}+\underline{Q}_{\mathrm{p}}
$$

It also represents the thermal energy demand which has to be covered by solar collectors.

Greenhouse heating is meant to be achieved by water flux radiators through which hot water is flowing after having been put in contact with heat storing materials at higher temperature (in this case, $32{ }^{\circ} \mathrm{C}$, as shown in tab.1). As the greenhouse inside temperature was chosen as $18{ }^{\circ} \mathrm{C}$, water temperature at the inlet of heat storing unit was chosen as $20{ }^{\circ} \mathrm{C}$, in order to suppose the maximum heat exchange in radiators. For the same reason, the outlet temperature from heat storing unit was fixed as $30^{\circ} \mathrm{C}$, such as slightly lower than the melting temperature of PCMs, that also represents the maximum temperature in heat storing unit. The corresponding temperature gap $\left(10{ }^{\circ} \mathrm{C}\right)$ was consi- dered high enough to permit radiators utilizations or underground tubes heat exchanges. Water flux regulation allows to control heat transfer intensity.

\subsection{Solar collectors}

For thermal energy supply, solar thermal plate collectors were considered, without any other auxiliary devices.

For their efficiency estimation and in order to calculate power supply, Bliss equation is used [Pauschinger 2003]:

$$
q_{s}^{\prime}=F_{z} \cdot\left[(\tau \cdot \alpha)_{e}-I_{\rho}-K_{c} \cdot\left(T_{i}^{\prime}-T_{u \alpha}\right)\right]
$$

$F_{r}$ : thermal efficiency factor ( 0.9 for liquid collectors) $\tau$ : transmissivity of solar panel

$\alpha$ : absorptivity of solar panel

$I_{\beta}$ : intensity of solar radiation reaching panel surface $\left(\mathrm{W} / \mathrm{m}^{2}\right)$

$K_{c}$ : thermal dispersion coefficient $\left(\mathrm{W} / \mathrm{m}^{2}{ }^{\circ} \mathrm{C}\right)$

$T_{i}^{f}$ : inlet temperature of $\mathrm{HTF}\left({ }^{\circ} \mathrm{C}\right)$

$T_{\text {out }}:$ external temperature $\left({ }^{\circ} \mathrm{C}\right)$

The product $(\tau \cdot \alpha)_{e}$ is the so called effective absorptivity-transmissivity factor and it is an overall parameter by which multiple in series phenomena of radiation transmittance and absorption, occurring through a double layer wall, are taken in account [Gemelli 2001]. It depends on the solar radiation angle, type of solar collectors and covering material. In this case a value as 0.8 was chosen, as for a single glass layer plate collector.

$K_{c}$ is an overall thermal coefficient for irradiative and convective heat exchanges between solar collector and external environment. It is a global simplified value that can be considered constant for the usual temperature ranges reached in these applications. Its common values are $3-5 \mathrm{~W} / \mathrm{m}^{2}{ }^{\circ} \mathrm{C}$ for selective plate and double layer, $4-6 \mathrm{~W} / \mathrm{m}^{2}{ }^{\circ} \mathrm{C}$ for simple plate and double layer, $7-8 \mathrm{~W} / \mathrm{m}^{2}{ }^{\circ} \mathrm{C}$ for simple plate and single layer [Gemelli 2001]. In the case study, a simple plate and single layer collector was taken in exam.

Solar radiation $I_{\beta}$ was calculated through the estimation of solar angles for each hour of every day of the year, by considering geographical coordinates of Bologna [Raffellini 2008]. Atmosphere transparency in October was fixed as 0.6 , and mean collectors inclination was considered as $30^{\circ}$. The HTF outlet temperature $\left(T_{o}^{f}\right)$ is then calculated by thermal energy balance:

$$
q_{n}^{\prime}=m_{f}^{\prime} c p_{f}-\left(T_{0}^{\prime}-T_{i}^{\prime}\right)
$$

$m_{f}^{\prime}$ heat transfer fluid mass flow $(\mathrm{kg} / \mathrm{h})$.

$c p_{f}$ specific heat $\left(\mathrm{kJ} / \mathrm{kg}{ }^{\circ} \mathrm{C}\right)$.

According to technical constraints for the optimal collectors functioning, $m_{f}$ is suggested to be in the range $10-50 \mathrm{~kg} / \mathrm{m}^{2}$ hour [Pauschinger 2003]. In this case, the lowest value was chosen, (12 1/min), in order to reach the highest HTF outlet temperature for the same value of $q^{\prime}$. As it is shown in eq. (6), inlet temperature of HTF, $T_{i}^{f}$, is an important parameter for col- 
lectors energy efficiency. This latter increases as lower as $T_{i}^{f}$ is. Nevertheless, $T_{i}^{f}$ needs to be fixed higher than phase change temperature of heat storing materials. For this reason, an accurate choice of these materials has to be achieved during system design procedure. In this case PCMs with melting temperature as $32{ }^{\circ} \mathrm{C}$ were chosen. Therefore, $T_{i}^{f}$ was fixed as $35^{\circ} \mathrm{C}$.

In order to simulate real collectors application (during daytime only), $m_{f}$ is fixed by the model algorithm as zero for all the turns (hours) in which $T_{i}^{f}=T_{o}^{f}$.

Model also permits to change total exposed surface of the collectors and even HTF mass flow (if necessary) in order to reach the required heat amount to be released inside the greenhouse.

\subsection{Water tank storing system}

The commonest system for thermal energy storage in solar applications is represented by the water tank storing unit. In this system, thermal energy is transferred during daytime by the HTF of solar collectors to a certain amount of water that hence increases its temperature (sensible heat). Subsequently this energy is released to the heating devices (radiators) through another fluid, usually water itself, during the hours in which heat is required. Because of density changes with temperature, hot water is moving to the top of the tank, while colder water is setting onto the bottom. For this reason, natural convective movements occur inside the tank, that is usually equipped with two different pipe coils. In the bottom zone of the tank, heat exchange with solar collectors HTF occurs, while on the top of it, heat exchange with water is established (see Fig. 2).

Thermal energy content as sensible heat of water inside the tank can be written as follows:

$$
Q_{n}=m_{s} \cdot c p_{s} \cdot \Delta T_{s}
$$

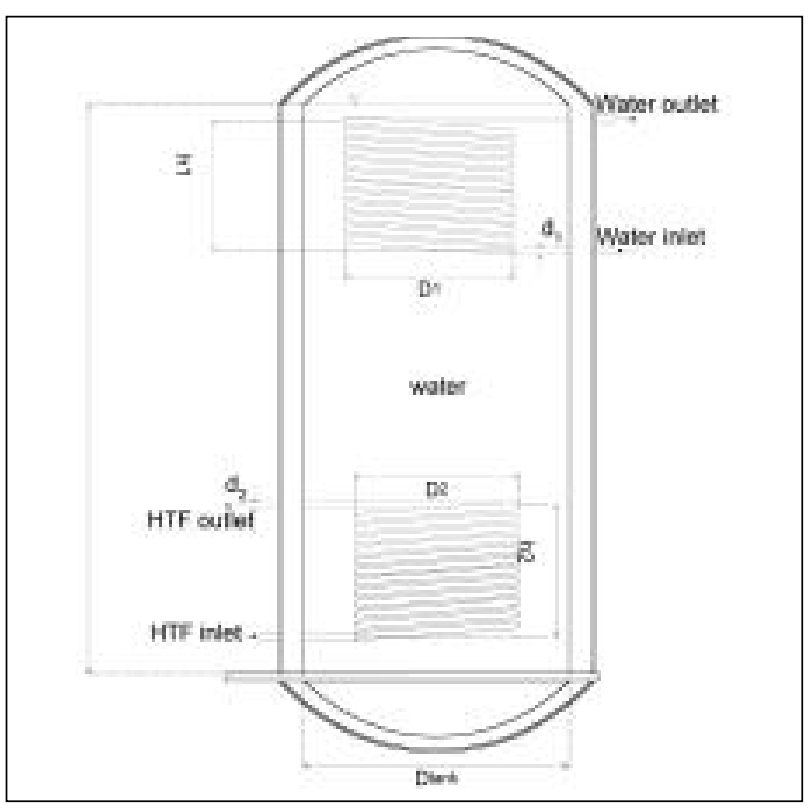

Fig. 2 - Water tank heat storing unit. $m_{w}:$ water mass $(\mathrm{kg})$

$c p_{w}$ : water average specific heat $\left(\mathrm{kJ} / \mathrm{kg}{ }^{\circ} \mathrm{C}\right)$

$\Delta T_{w}$ : temperature range of water inside the tank $\left({ }^{\circ} \mathrm{C}\right)$

In order to know minimum necessary amount of water to be used for heat storing $\left(m_{w}\right)$, a simplified procedure is followed: $\Delta T_{w}$ is fixed equal to the difference between the daily minimum temperature of HTF from the solar collectors and the required water temperature for greenhouses heating (minimum acceptable temperature range during the day); an average constant temperature $\left(T_{w}\right)$ of water is considered for $c p_{w}$ estimation and heat exchanges calculations; the highest continuous monotonic variation of thermal energy for the system during the day is chosen as $Q_{s}$. With these assumptions, $\mathrm{m}_{\mathrm{w}}$ is calculated as the minimum amount of water required to satisfy the highest thermal energy demand registered during the day.

Average temperature of water tank, $T_{w}$, is chosen equal as PCMs phase change temperature (see tab.1) in order to better compare the two heat storing systems. Heat exchanges between water inside the tank and both of the fluids flowing through the pipe coils are calculated by the same following equation [Colombo 2003]:

$$
Q_{i}^{\prime}=K_{j} \cdot A_{j} \cdot \Delta T_{j}^{h}
$$

$j$ : heat exchange fluids index ( 1 for water, 2 for HTF) $A$ : available surface $\left(\mathrm{m}^{2}\right)$ for heat exchange $\Delta T^{l n}$ : logarithmic average temperature difference between heat exchange fluid " $j$ " and water inside the tank $\left({ }^{\circ} \mathrm{C}\right)$.

$K$ : overall thermal transfer coefficient $\left(\mathrm{W} / \mathrm{m}^{2}{ }^{\circ} \mathrm{C}\right)$.

$$
K=\frac{1}{\frac{1}{h_{j}}+\frac{s}{\lambda}+\frac{1}{h_{s}}}
$$

$h_{i}$ : thermal convective coefficient of heat transfer fluid " $j$ " $\left(\mathrm{W} / \mathrm{m}^{2}{ }^{\circ} \mathrm{C}\right)$

$s$ : thickness of solid wall (m)

$\lambda$ : thermal conductivity of solid wall $\left(\mathrm{W} / \mathrm{m}{ }^{\circ} \mathrm{C}\right)$

$h_{w}$ : thermal convective coefficient of water inside the tank $\left(\mathrm{W} / \mathrm{m}^{2}{ }^{\circ} \mathrm{C}\right)$.

$h_{w}$ is calculated through the Nusselt number, whose general expression is:

$$
N u=\frac{h \cdot d}{\mu}
$$

$d$ : characteristic length (m). In the case of water inside the tank it is considered as the tank diameter $D_{\text {tank }}$. $\mu$ : dynamic viscosity $\left(\mathrm{N} \mathrm{s} / \mathrm{m}^{2}\right)$

In the specific case of water inside the tank, $N u_{w}$ is calculated as follows [Holman 1990]:

$$
N u_{s}=0.17\left(G r_{*} \cdot P r_{*}\right)
$$

$G r_{w}:$ Grashof number $=9.81 \cdot \rho_{w}{ }^{2} \cdot D_{\text {tank }}{ }^{3} \cdot \beta_{w} \cdot \Delta T_{w} / \mu_{w}{ }^{2}$ $\operatorname{Pr}_{w}$ : Prandtl number $=\mu_{w} c p_{w} / k_{w}$ $\beta_{w}$ : thermal expansion coefficient of water $\left(\mathrm{K}^{-1}\right)$ 
$h_{j}$ is also calculated by eq. (11), but in this case Nusselt number is:

$$
\mathrm{Nu}_{j}=0.023 \mathrm{Re}_{j}^{0.3} \mathrm{Pr}_{j}^{0.4}
$$

$P r_{j}=\mu_{j} c p_{j} / k_{j}$

$\operatorname{Re}_{j}$ : Reynolds number, $\rho_{j} \cdot d_{j} \cdot v_{j} / \mu_{j}$

$\rho_{j}$ fluid density $\left(\mathrm{kg} / \mathrm{m}^{3}\right)$

$d_{j}$ : inner pipe diameter $(\mathrm{m})$

$v_{j}$ : fluid velocity $(\mathrm{m} / \mathrm{s})$

$\mu_{j}$ : fluid dynamic viscosity $\left(\mathrm{N} \mathrm{s} / \mathrm{m}^{2}\right)$

$h_{j}$ value is then corrected in order to consider circular shape of the coil, by using the following expression:

$$
h_{j}^{\prime}=h_{j} \cdot\left(1+3.5 \frac{d_{j}}{D_{j}}\right)\left(\mathrm{W} / \mathrm{m}^{2}{ }^{\circ} \mathrm{C}\right)
$$

$h_{j}^{\prime}:$ corrected value

$h_{j}$ : calculated value

$D_{j}$ : spiral diameter $(\mathrm{m})$

\subsection{PCMs storing system}

The water tank heat storing unit is compared with a latent heat storage system based on PCMs utilization.

These are disposed in rectangular plate heat exchangers through which HTF from collectors and water from radiators are forced to counter-current flow. (see Fig. 3).

Each plate is made of a very thin copper rectangular shell which PCMs are filled in. They are separated each other by very thin channels, as well, through which heat exchange fluids alternatively flow.

In this way, a large heat exchange surface is achieved and poor heat transfers are avoided, in spite of the often too low thermal conductivity of PCMs.

Heat exchange is still calculated by eq. (9), where $\Delta T^{l n}$ is in this case the logarithmic average temperature difference between heat exchange fluid $(j)$ and PCMs at their melting temperature, and $A_{j}$ is the total contact surface between fluid $(j)$ and copper plates. More over, $K_{j}$ has a different expression as well. By neglecting convective heat transfer by PCMs in liquid phase, it can be written as:

$$
K_{\gamma}=\frac{1}{\frac{1}{h_{j}}+\frac{s^{4}}{\lambda^{\prime}}+\frac{s_{\mathrm{pan}}}{\lambda_{p w}}}
$$

$h_{\dot{1}}$ : thermal convective coefficient of heat transfer fluid " $j$ " $\left(\mathrm{W} / \mathrm{m}^{2}{ }^{\circ} \mathrm{C}\right)$

$s^{\prime}$ : thickness of copper plates $(\mathrm{m})$

$\lambda$ ': thermal conductivity of copper plates $\left(\mathrm{W} / \mathrm{m}{ }^{\circ} \mathrm{C}\right)$

$s_{p c m}:$ thickness of PCMs (m)

$\lambda_{p c m}^{p c m}:$ thermal conductivity of PCMs $\left(\mathrm{W} / \mathrm{m}^{\circ} \mathrm{C}\right)$

Nusselt number for heat exchange fluids is calculated by the following expressions [Holman 1990]:

$$
\begin{array}{ll}
\mathrm{Nu}_{j}=0.664 \mathrm{Re}_{j}^{0.5} \mathrm{Pr}_{j}^{1 / 3} & \left(\operatorname{Re}>5 \cdot 10^{5}\right) \\
\mathrm{Nu}_{j}=0.037 \mathrm{Re}_{j}^{4 / 3} \mathrm{Pr}_{j}^{13} & \left(\operatorname{Re}<5 \cdot 10^{5}\right)
\end{array}
$$

In which $R e_{j}=\rho_{j} \cdot l_{j} \cdot v_{j} / \mu_{j}$ with $l_{j}=$ plate length (m).

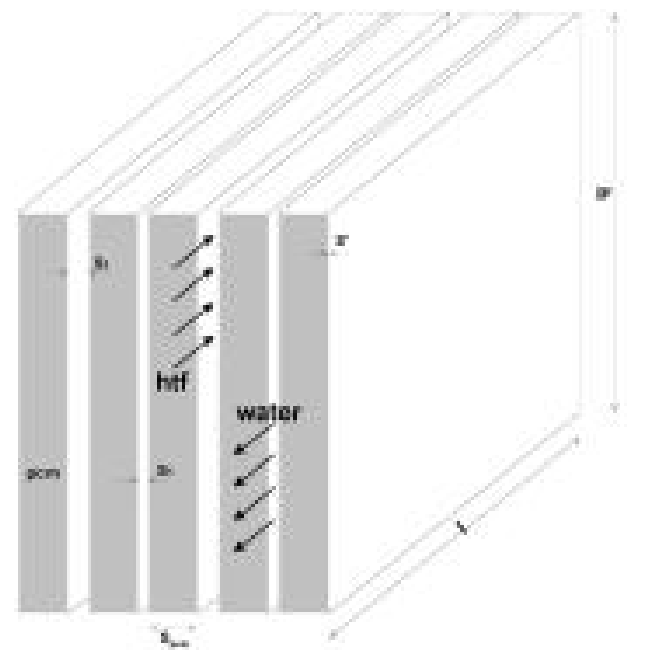

Fig. 3 - Latent heat storing unit.

$h_{j}$ is then calculated by eq. (11).

Also in this case inlet and outlet temperatures of water are constant in time (respectively $20^{\circ} \mathrm{C}$ and 30 ${ }^{\circ} \mathrm{C}$ ), and heat exchange is regulated by changing mass flux $(\mathrm{kg} / \mathrm{h})$ on the basis of energy demand. HTF from the solar collectors, instead, is circulating through the storage unit only during the light hours of the day, that means only when $T_{i}^{f} \neq T_{o}^{f}$. Indeed, HTF flux is constant in time and it changes its temperature on the basis of solar radiation.

Thanks to the assumption of constant temperature of PCMs during phase change phenomena (heat storage and release), both heat exchanges between them and HTF or water can be considered independent each other, even during the hours they occur simultaneously.

The phase change material considered in this case is the inorganic hydrate salt $\mathrm{Na}_{2} \mathrm{SO}_{4} \cdot 10 \mathrm{H}_{2} \mathrm{O}$. Its main characteristics are [Zalba 2003]:

\begin{tabular}{|l|l|}
\hline melting temperature $\left({ }^{\circ} \mathrm{C}\right)$ & 32 \\
\hline latent heat $(\mathrm{kJ} / \mathrm{kg})$ & 251 \\
\hline thermal conductivity $\left(\mathrm{W} / \mathrm{m}^{\circ}{ }^{\circ} \mathrm{C}\right)$ & 0.544 \\
\hline density $\left(\mathrm{kg} / \mathrm{m}^{3}\right)$ & 1458 \\
\hline
\end{tabular}

TABLE 1 - Phase change material properties.

Its melting temperature, indeed, is high enough to have also water temperature acceptably high for greenhouse heating, and, on the other hand, it permits to maintain inlet HTF temperature to solar collectors relatively low.

\section{Results and discussions}

Both the thermal energy storing units described above were investigated by an analytical model (by Labview software), in order to check their technical 
feasibility in low temperature applications

They were thought to be used in a greenhouse heating application carried out by thermal solar collectors, in order to equalize the different temporal daily peaks of energy supply and demand. According to the greenhouse dimensions and its calculated heat looses, (as described in par. 2.1), the solar collector characteristics (shown in par. 2.2) and the considered climate conditions, a $215 \mathrm{~m}^{2}$ total exposed surface of collectors resulted necessary to maintain the greenhouse inside temperature as $18^{\circ} \mathrm{C}$ for all the day. This first result was achieved by balancing cumulative daily heat demand (kWh) with total thermal energy supplied by solar collectors during the day. By putting this balance equal to zero, collectors surface is obtained. The relatively high value can be maybe explained by the assumption no temperature fluctuations inside the greenhouse occur, so that air natural cooling sensible heat from higher temperature to $18{ }^{\circ} \mathrm{C}$ is neglected as thermal energy supply. Anyway, result is comparable with greenhouse roof surface $\left(242 \mathrm{~m}^{2}\right)$.

Daily thermal energy curves (by hour) of heat supply and demand, whose cumulative heat daily balance is equal to zero, are shown in Fig. 4.

These two daily energy trends were then separately considered as input data to design heat storage units.

Indeed, dimensioning of heat storage systems was carried out by achieving through the model algorithm similar daily curves, representing eq. (9) as a function of time during the day. They were obtained in the two cases separately (water tank and PCMs unit) and for both of the two fluids involved in heat exchange (radiators water and HTF for solar collectors, $j=1,2$ ). In this manner, a graphical representation of heat exchanges in both of the systems were obtained.

In order that heat storing units are correctly designed, heat exchanges daily curves must be as coincident as possible to the energy supply and demand ones obtained previously (fig. 4).

Therefore, after choosing acceptable and commercial values for pipes materials, diameters and thickness, all the other main dimensions of both of the units were fixed in order to best fit heat exchange curves with energy supply/demand ones (fig. 5 and 6). Among all the possible solutions, the ones showing minimum units

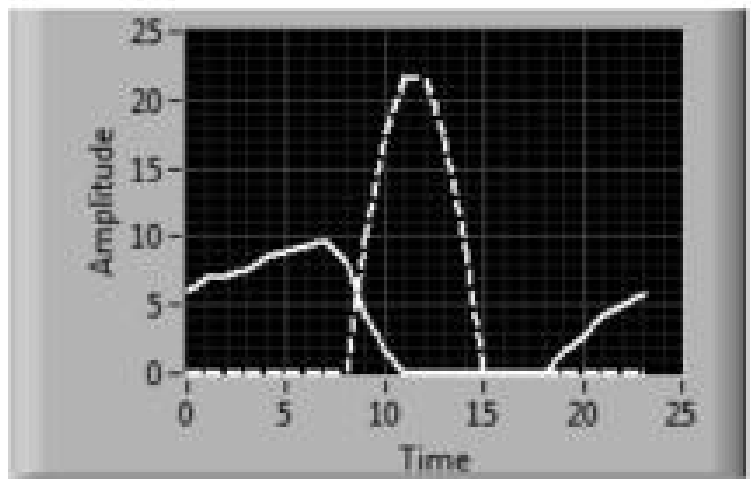

Fig. 4 - Energy demand daily curve (continuous) and energy supply daily curve (broken) $(\mathrm{kW})$.

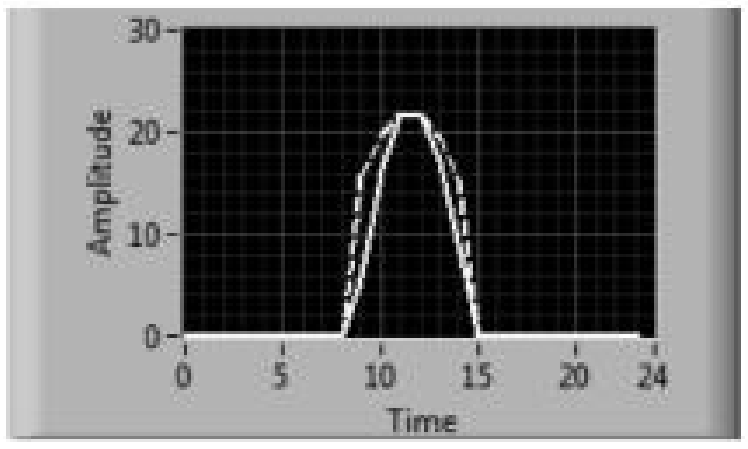

Fig. 5a- HTF heat exchange curve (broken) and energy supply curve (continuous) for water tank storing unit $(\mathrm{kW})$.

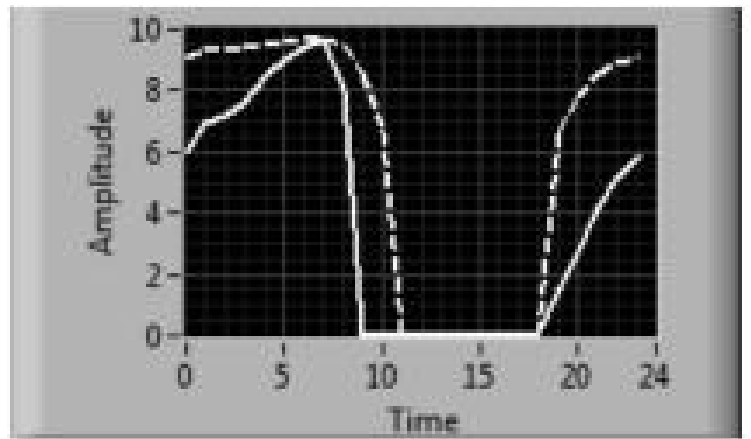

Fig. 5b- Water heat exchange curve (broken) and energy demand curve (continuous) for water tank storing unit $(\mathrm{kW})$.

volumes and minimum heat storing materials amounts (water or PCMs, respectively) were finally chosen as the best design configurations (table 2 and 3 ).

These data clearly show that latent heat storage system require a total unit volume lower than water tank system one, with a ratio as around 1:7. This is quite an expected result due to the deep difference between latent and sensible heats stored in the two different systems. A more interesting result is latent heat storing unit seems to better fit energy demand daily variations, in spite of low thermal conductivity of PCMs. (Fig. 5b and 6b).

This is due to the large available heat exchange surface it is possible to achieve in the design configuration adopted in this case. On the contrary, in order to maintain acceptable dimensions, this is not possible for water tank unit.

Another interesting result from developed analytical model is the variation of solid-liquid phase mixture of considered PCM during the day and according to heat exchanges.

Figure 7 shows results for the examined case study. As it can be seen, mixture always includes both solid and liquid phase. Indeed, this is a fundamental assumption for model algorithm in order to assure only latent heat is involved in heat exchanges for PCMs unit and its temperature is constant during operation.

\section{Conclusions}

Two different heat storing systems were investigated 


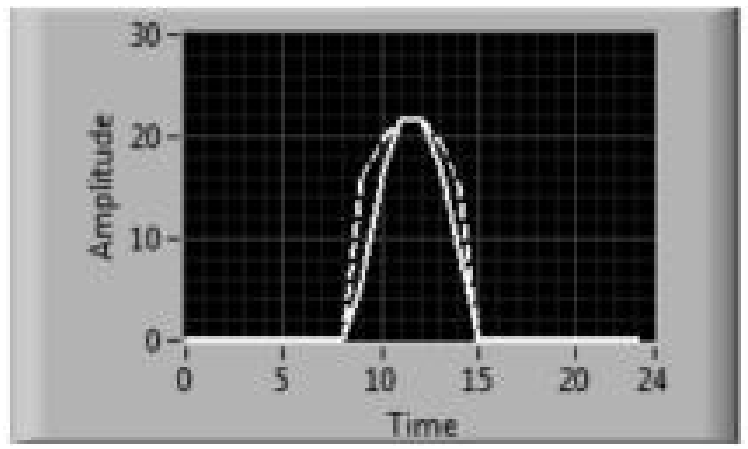

Fig. 6a- HTF heat exchange curve (broken) and energy supply curve (continuous) for PCMs storing unit (kW)

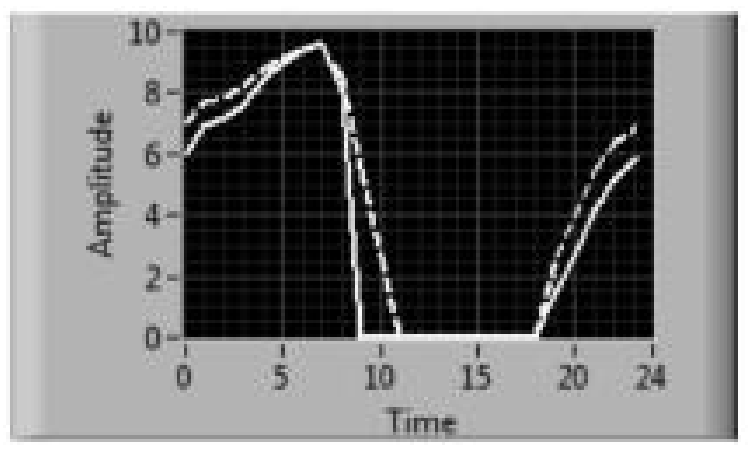

Fig. 6b- Water heat exchange curve (broken) and energy demand curve (continuous) for PCMs storing unit $(\mathrm{kW})$.

for low temperature applications by means of a numerical simulation model.

As a case study, a thermal solar collectors greenhouse heating application was chosen and local zone was considered for climate data retrieval.A $840 \mathrm{~m}^{3}$ total volume greenhouse was considered, with a constant inside temperature of $18{ }^{\circ} \mathrm{C}$ (in October). At this scope, $215 \mathrm{~m}^{2}$ total surface panels are required, with any other auxiliary devices.

The two heat storage systems considered here were a traditional water tank, equipped with two pipe coils for heat exchanges, and a latent heat storage unit based on PCMs $\left(\mathrm{Na}_{2} \mathrm{SO}_{4} \cdot 10 \mathrm{H}_{2} \mathrm{O}\right)$. This latter has been thought as a series of copper plate shells in which PCM is filled in. HTF from solar collectors and water

\begin{tabular}{|l|l|}
\hline Number of plates & 50 \\
\hline Plate length $(\mathrm{m})$ & 2 \\
\hline Plate height $(\mathrm{m})$ & 1.5 \\
\hline PCMs plate thickness smon $(\mathrm{m})$ & 0.01 \\
\hline Copper shell thickness s' (m) & 0.001 \\
\hline HTF channel width sz $(\mathrm{m})$ & 0.0012 \\
\hline Water channel width si $(\mathrm{m})$ & 0.004 \\
\hline PCM amount $(\mathrm{kg})$ & 2187 \\
\hline Total volume $\left(\mathrm{m}^{3}\right)$ & 2.18 \\
\hline
\end{tabular}

TABLE 2 - PCMs heat storage unit dimensions.

\begin{tabular}{|l|l|}
\hline Tank diameter $(\mathrm{m})$ & 2.5 \\
\hline Tank total height $(\mathrm{m})$ & 3.22 \\
\hline Water content $(\mathrm{kg})$ & 15715 \\
\hline HTF pipe length $(\mathrm{m})$ & 110 \\
\hline Water pipe length $(\mathrm{m})$ & 45 \\
\hline HTF pipe inner diameter $\mathrm{d}_{2}(\mathrm{~m})$ & 0.02 \\
\hline Water pipe inner diameter $\mathrm{d}_{1}(\mathrm{~m})$ & 0.02 \\
\hline HTF pipe thickness $(\mathrm{m})$ & 0.0025 \\
\hline Water pipe thickness $(\mathrm{m})$ & 0.0025 \\
\hline HTF pipe height $\mathrm{h}_{2}(\mathrm{~m})$ & 0.88 \\
\hline Water pipe height $\mathrm{h}_{1}(\mathrm{~m})$ & 0.36 \\
\hline HTF pipe spiral diameter $\mathrm{D}_{2}(\mathrm{~m})$ & 2 \\
\hline Water pipe spiral diameter $\mathrm{D}_{1}(\mathrm{~m})$ & 2 \\
\hline Water tank average $\mathrm{T}\left({ }^{\circ} \mathrm{C}\right)$ & 32.5 \\
\hline Total volume $\left(\mathrm{m}^{3}\right)$ & 15.8 \\
\hline
\end{tabular}

TABLE 3 - Water tank heat storage unit dimensions.

for greenhouse heating lick these plates through thin channel so that they exchange energy with material inside by convective heat exchange.

Due to the low temperature differences $(\Delta T)$ at which heat exchanges occur, a very deep difference of storing material amounts resulted for the two cases. For the water tank unit, only sensible heat is exchanged with a very low $\Delta T$. This means a large amount of water is necessary for heat supply (about $16 \mathrm{~m}^{3}$ total volume).

In latent heat storing unit, instead, a large amount of heat is exchanged by phase change phenomena, so that much less material is required. About seven times less total volume is required in this case in respect with water tank unit $\left(2.2 \mathrm{~m}^{3}\right)$. More over, latent heat storing unit equipment permits an higher available surface for heat exchange among involved fluids, so that it is easier to rapidly fit energy supply and demand fluctuations during daytime. Analytical model (by LabView software) shows heat exchanges daily curves for both the heat storage units and for both the

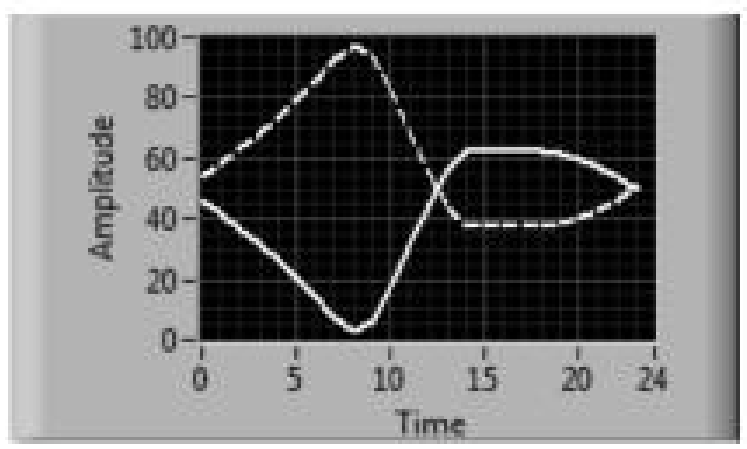

Fig. 7 - Solid percentage (broken) and liquid percentage (continuous) of PCM phase mixture during the day. 
heat transport fluids (HTF from solar collectors and water for radiators). All these curves are superimposed on the previously calculated energy supply/demand curves, in order to check efficiency of heat exchanges and achieve units dimensions.

As said, it seems latent heat unit has an higher flexibility in following energy demand and supply daily variations, in spite of low thermal conductivity of PCM. Nevertheless, no economic analysis is presented here and then any real feasibility study is not possible yet, according to these preliminary results only.

\section{References}

ANSI/ASAE EP406.4 JAN03. Heating, Ventilating and Cooling Greenhouses. ASAE Standards 2003, pp.699-700.

Basso F. Difesa del Suolo e Tutela dell'Ambiente. Pitagora 1995, p.82.

Caprara C, Stoppiello G. Heat storage system with phase change materials in cogeneration units: study of preliminary model. Journal of Agricultural Engineering, 2008, 4, 29-38.

Casalicchio G. Geopedologia con elementi di Geoarcheologia. Pitagora 2006, p. 683.

Cavazza L. Fisica del Terreno Agrario. UTET 1981, p. 524.

Colombo G. Manuale dell'Ingegnere. Nuovo Colombo, Hoepli, 84 ed., vol. I, B93-B102, 2003.

Gemelli M, Micangeli A. I sistemi solari attivi. Scaldare l'acqua e gli ambienti con il Sole, Torino, 2001.

Holman J P. Heat transfer. 7th ed., McGraw-Hill, 1990.

Mehling H, Cabeza L F, Hippeli S, Hiebler S. PCM-module to improve hot water heat storeswith stratification. Renewable Energy, 2003, 28, 699-711.

Parker B F. Solar Energy in Agriculture. Elsevier 1991, p. 218.

Pauschinger T, Menard M, Schulz M. Impianti solari termici - Manuale per la progettazione e la costruzione. Ambiente Italia, 2003.

Raffellini G. Techniques for renewable energies, lecture notes. Architecture Technologies and Design Department, University of Florence, 2008.

Worley J. Greenhouses, heating, cooling and ventilation, College of Agricultural and Environmental. Science and Family and Customer Science, University of Georgia, 2005.

Yagi J, Akiyama T. Storage of thermal energy for effective use of waste heat from industries. Journal of Materials Processing Technology, 1995, 48, 793-804.

Zalba B, Marin J, Cabeza L F, Mehling H. Review on thermal energy storage with phase change materials, heat transfer analysis and applications. Applied thermal Engineering, 2003, 23, 251-283.

\section{SUMMARY}

In order to use solar radiation as thermal energy source, heat storage equipments result necessary in each application where continuous supply is required, because of the natural unsteady intensity of radiation during the day.

Thermal solar collectors are especially suitable for low temperature applications, since their efficiency decreases when an high inlet temperature of fluid flowing through them is established.
On the other hand, low temperatures and low temperature gaps, above all, make very difficult to use traditional sensible heat storing units (water tanks), because of the very large amounts of material required.

In this work, a traditional sensible heat storage system is compared with a latent heat storing unit based on phase change materials (PCMs).

As a case study, a $840 \mathrm{~m}^{3}$ greenhouse heating application was considered with an inside constant temperature of $18^{\circ} \mathrm{C}$. It is thought to be heated by using single layer plate thermal solar collectors as energy source.

Inlet temperature of the collectors fluid (HTF) was fixed at $35^{\circ} \mathrm{C}$ (little higher than melting temperature of PCMs) and a constant flux of $121 / \mathrm{m}^{2}$ hour was established as technical usual value.

At these conditions, $215 \mathrm{~m}^{2}$ solar panels exposed surface resulted necessary.

The sensible heat storage system considered here is a traditional water tank storing unit equipped with two pipe coils, respectively for heat exchanges with HTF from collectors and water flux for greenhouse heating.

Available DT for heat exchange is estimated as the difference of minimum HTF temperature (in outlet from the collectors) and the required water temperature for greenhouse heating.

The latent heat storing unit is instead a series of copper rectangular plate shells which a phase change material is filled in $\left(\mathrm{Na}_{2} \mathrm{SO}_{4} \cdot 10 \mathrm{H}_{2} \mathrm{O}\right)$. Heat transfer fluids flow through thin channels between adjacent plates, so that a large heat exchange available surface is achieved.

The developed computational model (Labview software) permits to superimpose heat exchanges daily curves between heat storing materials and heat transport fluids (for both of the fluids and the heat storing equipments) on the energy supply/demand ones, respectively calculated on the basis of greenhouse energy demand and solar collectors dimensions, characteristics and efficiency.

In this manner, units design is achieved by changing thermal energy storing units dimensions, in order that the corresponding heat exchange curves coincide with the previously calculated ones. Successively, among all the possible configurations, the ones showing lower units volumes and less amount of storing materials are chosen as the optimal design solutions.

It has been proven that PCMs materials are much more suitable for low temperature applications than sensible heat storing materials (water).

In the case of water tank, an about $15.8 \mathrm{~m}^{3}$ total volume is required while for PCMs equipment the total volume of storing unit is reduced to about $2.2 \mathrm{~m}^{3}$, such as about seven times total volume less.

Besides, according to the simplified and steady state model calculations, PCMs unit shows a better response to the hourly energy fluctuations of solar collectors and greenhouse demand than water tank unit. This is especially due to the high available exchange surface achieved in proposed arrangement.

Keywords: thermal energy storage, phase change materials, heat exchange, greenhouse heating, thermal solar collectors. 